\title{
miR-181c expression in neuroblastoma children and proliferation of neuroblastoma M17 cells
}

\author{
XUEYAN XU ${ }^{1}, \mathrm{JUN}^{\mathrm{W}} \mathrm{U}^{2}$, GUIFANG REN ${ }^{1}$ and QIANG HU ${ }^{3}$ \\ Departments of ${ }^{1}$ Nursing, ${ }^{2}$ Medical Equipment and ${ }^{3}$ Pediatric Surgery, \\ Weifang People's Hospital, Weifang, Shandong 261041, P.R. China
}

Received September 5, 2018; Accepted June 28, 2019

DOI: 10.3892/ol.2019.10602

\begin{abstract}
Expression level of miR-181c in neuroblastoma children and its effect on proliferation of neuroblastoma M17 cells were investigated. Fifty-seven neuroblastoma patients admitted to Weifang People's Hospital from January 2013 to December 2017 were selected and their cancer tissues and normal adjacent tissues were obtained. The expression level of miR-181c in the tissues of neuroblastoma patients was measured. The association of miR-181c expression level with the clinical and pathological features was analyzed. Neuroblastoma M17 cells were cultured in vitro, and cells were transfected and divided into miR-181c and blank groups. MTT assay was used to observe the proliferation of cells at 24,48 and $72 \mathrm{~h}$. The results of RT-qPCR detection showed that the expression level of miR-181c was significantly lower in neuroblastoma cancer tissues than that in adjacent tissues, with a statistically significant difference $(\mathrm{t}=18.570, \mathrm{P}<0.001)$. The expression of miR-181c was not associated with sex $(\mathrm{P}=0.632)$, but associated with age, differentiation degree, lymph node metastasis, distant metastasis and the International Neuroblastoma Risk Group Staging System (INRGSS), with statistically significant differences $(\mathrm{P}<0.05)$. Following transfection of miR-181c into M17 cells, the results of MTT assay showed that there was no significant difference between the two groups in the proliferation of M17 cells at $24 \mathrm{~h}(\mathrm{P}>0.05)$. After $48 \mathrm{~h}$, differences between the two groups were recorded. Proliferation of M17 cells was significantly lower in the miR-181c group than that in the blank group, with a statistically significant difference $(\mathrm{P}<0.05)$. Age, differentiation degree, lymph node metastasis, distant metastasis, and INRGSS staging were independent risk factors for neuroblastoma $(\mathrm{P}<0.05)$. miR-181c has certain clinical significance in evaluating pathogenesis, early diagnosis and treatment of patients with neuroblastoma.
\end{abstract}

Correspondence to: Dr Qiang Hu, Department of Pediatric Surgery, Weifang People's Hospital, 151 Guangwen Street, Weifang, Shandong 261041, P.R. China

E-mail: hd922a@163.com

Key words: miR-181c, neuroblastoma, cell proliferation, neuroblastoma M17 cell

\section{Introduction}

Clinically, neuroblastoma, also known as neurocytoma, is one of the most common extracranial malignant solid tumors in children, accounting for $6-10 \%$ of all tumors in children $(1,2)$. The incidence in children $<15$ years of age is $9,700,000$ every year in the United States, with $>50 \%$ in infants before the age of 2 years (3). Derived from neural stem cells, neuroblastoma belongs to neuroendocrine tumors. Its primary site is often concealed and extensive, which brings certain difficulties to clinical diagnosis. In addition, tumor cells have extremely high malignancy, prone to early multiple metastases $(4,5)$.

As a group of non-coding RNAs consisting of approximately 19-25 nucleotides in length, miRNAs can horizontally regulate the expression of multiple genes after transcription, thus functioning as oncogenes or tumor suppressor genes (6-8). A study has confirmed that the pathological process of tumors is related to the expression of serum miRNAs that play an important role in the occurrence, development, diagnosis and prognosis of tumors (9). In recent years, research has shown that miR-181c may play a key role in the occurrence and development of tumors and autoimmune diseases (10). For example, low expression in a variety of tumors shows a negative regulatory effect on the proliferation and metastasis of tumor cells, such as nasopharyngeal carcinoma (11). However, studies on miR-181c in neuroblastoma are rare. This study analyzed the expression of miR-181c in neuroblastoma patients and its effect on the proliferation of neuroblastoma M17 cells, in order to provide clinical value in the occurrence and development, prediction and prognosis, and diagnosis and treatment of neuroblastoma.

\section{Patients and methods}

Clinical information. Fifty-seven neuroblastoma patients admitted to Weifang People's Hospital (Weifang, China) from January 2013 to December 2017 were selected, and their cancer tissues and normal adjacent tissues were obtained. In total, 32 males and 25 females were included in the study, 0-27 years of age, with an average age of $5.64 \pm 2.37$ years. Inclusion criteria: all cancer tissue specimens were confirmed by pathology, and the adjacent tissues were confirmed to be without cancer or inflammatory cell infiltration; patients with complete records were included; and patients who had 
not received relevant medical treatment in other hospitals. Exclusion criteria: patients during pregnancy or lactation; patients with other severe diseases or tumors; patients with communication disorders or cognitive impairment. The study was approved by the Ethics Committee of Weifang People's Hospital. Patients or their families signed the informed consent form and cooperated with the medical staff to complete the relevant medical treatment. The basic information of patients is shown in Table I.

Main materials. Human neuroblastoma M17 cells [human neuroblastoma cell line BE(2)-M17; cat. no. CL-0262] were purchased from Shanghai Chunmai Biotechnology Co.; RPMI-1640 medium was purchased from Hyclone (GE Healthcare Life Sciences); reverse transcription kit from Beyotime Institute of Biotechnology; RT-qPCR kit from Takara Biotechnology Co., Ltd.; TRIzol kit from Shanghai Pufei Biotechnology Co., Ltd.; fetal bovine serum (FBS) and dimethyl sulfoxide (DMSO) from Sigma-Aldrich (Merck KGaA); UV-3100PC spectrophotometer from Shanghai MeiPuda Co., Ltd.; Lipofectamine 2000 transfection reagent from Invitrogen (Thermo Fisher Scientific, Inc.), and MTT detection kit from Thermo Fisher Scientific, Inc.

$R T-q P C R$ detection of miR-181c expression. One-step extraction method was used to extract total RNA from neuroblastoma cancer tissues and adjacent tissues using the TRIzol kit. The specific steps were carried out in strict accordance with the manufacturer's instructions. UV-3100PC spectrophotometer was used to measure the concentration and purity of the extracted RNA, and 1\% denaturing agarose gel electrophoresis to detect the integrity of extracted RNA. The extracted RNA was reverse transcribed to obtain cDNA, that was used as a template for the experiment. The primer sequence was designed and synthesized by Shanghai Shenggong Bioengineering Co., Ltd., with $\beta$-actin as the internal reference gene. RNA $(1 \mu \mathrm{g})$ was added to the reverse transcription system, and the reverse transcription procedure was $37^{\circ} \mathrm{C}$ for $15 \mathrm{~min}, 85^{\circ} \mathrm{C}$ for $5 \mathrm{sec}$, and $4^{\circ} \mathrm{C}$ for $10 \mathrm{~min}$. RT-qPCR: amplification was performed on a Light Cycler Real-time PCR instrument (Bio-Rad Laboratories, Inc.) with the reverse transcription product cDNA as a template. Reaction system: $10 \mu 1$ of SYBR Premix Ex Taq (2X) (Takara Biotechnology Co., Ltd.), each of $0.4 \mu \mathrm{l}$ of 5' and 3' primers, $2.0 \mu \mathrm{l}$ of DNA template, sterilized, double distilled water added to $20 \mu \mathrm{l}$. Reaction conditions: pre-denaturation at $95^{\circ} \mathrm{C}$ for $30 \mathrm{sec}$, denaturation at $95^{\circ} \mathrm{C}$ for $5 \mathrm{sec}$, and at $60^{\circ} \mathrm{C}$ for $20 \mathrm{sec}$. Melting conditions: $95^{\circ} \mathrm{C}$ for $30 \mathrm{sec}, 65^{\circ} \mathrm{C}$ for $15 \mathrm{sec}$, and $95^{\circ} \mathrm{C}$ for $20 \mathrm{sec}$. Each group of samples was repeated 3 times. The $2^{-\Delta \mathrm{Ca}}$ method was used to analyze the expression level of miR-181c in the samples (12). Primer sequences are shown in Table II.

MTT assay detection of proliferation. Human neuroblastoma M17 cells were cultured and proliferated in RPMI-1640 medium. M17 cells were cultured at $37^{\circ} \mathrm{C}$, with $\mathrm{pH}$ 6.8-7.4 and $5 \% \mathrm{CO}_{2}$. miR-181c was subjected to PCR amplification and purification. The PCR product was then recovered. The product and the vector plasmid containing the green fluorescent protein reporter gene were separately digested and purified by Age and EcoRI, and the products were ligated
Table I. Basic information of 57 neuroblastoma patients [n(\%)].

\begin{tabular}{|c|c|}
\hline Factors & Cases $(n=57)$ \\
\hline \multicolumn{2}{|l|}{ Age (years) } \\
\hline$<15$ & $45(78.95)$ \\
\hline$\geq 15$ & $12(21.05)$ \\
\hline \multicolumn{2}{|l|}{ Sex } \\
\hline Male & $32(56.14)$ \\
\hline Female & $25(43.86)$ \\
\hline \multicolumn{2}{|l|}{ Arthralgia } \\
\hline Yes & $39(68.42)$ \\
\hline No & $18(31.58)$ \\
\hline \multicolumn{2}{|l|}{ Periorbital dark circles } \\
\hline Yes & $21(36.84)$ \\
\hline No & $36(63.16)$ \\
\hline \multicolumn{2}{|l|}{ Pathological typing } \\
\hline NB less matrix type & $18(31.58)$ \\
\hline GNB rich matrix type & $23(40.35)$ \\
\hline GN mature type & $11(19.30)$ \\
\hline 3NB nodule type & $5(8.77)$ \\
\hline \multicolumn{2}{|l|}{ Incidence site } \\
\hline Adrenal gland & $23(40.35)$ \\
\hline Cervix & $2(3.51)$ \\
\hline Pleural cavity & $11(19.30)$ \\
\hline Abdominal cavity & $18(31.58)$ \\
\hline Pelvic cavity & $2(3.51)$ \\
\hline Others & $1(1.75)$ \\
\hline \multicolumn{2}{|l|}{ INRGSS } \\
\hline Stage L1 & $22(38.60)$ \\
\hline Stage L2 & $23(40.35)$ \\
\hline Stage M & $10(17.54)$ \\
\hline Stage MS & $2(3.51)$ \\
\hline
\end{tabular}

$\mathrm{NB}$, neuroblastoma; GNB, ganglioneuroblastoma; GN, ganglioneuroma; INRGSS, International Neuroblastoma Risk Group Staging System.

overnight at $16^{\circ} \mathrm{C}$ to obtain the vector. The vector was used to transform DH5a competent bacteria, and the positive clones were screened and sent to Shanghai Jima Pharmaceutical Technology Co., Ltd. for sequencing. miR-181c was transfected into cells in strict accordance with the liposome Lipofectamine 2000 instructions. miR-181c expression vectors were divided into the miR-181c group and the blank group with blank vector (without tumor suppressor), cultured together with human neuroblastoma M17 cells in RPMI-1640 medium, in an incubator at $37^{\circ} \mathrm{C}$ and $5 \% \mathrm{CO}_{2}$ for $24 \mathrm{~h}$. Untreated M17 cells were used as the control group.

After transfection, human neuroblastoma M17 cells were prepared into a single-arranged cell suspension. Cells were routinely seeded and cultured in a 96-well culture plate. A part of the cultured cells was taken out, and $20 \mu \mathrm{l}$ of MTT $(5 \mathrm{mg} / \mathrm{ml})$ solution were added, and continuously cultured at $37^{\circ} \mathrm{C}$ for $4 \mathrm{~h}$. The supernatant containing impurities was 
Table II. Primer sequences of miR-181c and internal reference.

\begin{tabular}{lll}
\hline Genes & \multicolumn{1}{c}{ Upstream primers } & \multicolumn{1}{c}{ Downstream primers } \\
\hline miR-181c & 5'-CGAAGCTTATGTTCAGGACCA & 5'-CCCTCGAGGGGCGCAGAT \\
$\beta$-actin & AACGATCTGCGC-3' & CGTTTGGTCCTGAACAT-3' \\
\hline
\end{tabular}

aspirated, and the DMSO preparation was added, shaken for 15 min on a horizontal shaker. An ELISA instrument was used to measure the OD values at a wavelength of $480 \mathrm{~nm}$ at 24 , 48 and $72 \mathrm{~h}$, and the growth curve was plotted.

Soft agar colony formation assay to determine proliferation. The bottom agar was prepared. Fully melted 5\% agar and fresh complete medium (pre-warmed at $37^{\circ} \mathrm{C}$ ) were mixed evenly at a ratio of $1: 9$ at $40^{\circ} \mathrm{C}$, and then added to a Petri dish (60-mm diameter) containing $0.5 \mathrm{ml}$ of agar medium per dish. The agar was completely solidified at room temperature. miR-181c was used to transfect cells in strict accordance to the manufacturer's instructions of liposome Lipofectamine 2000. The miR-181c expression vector was divided into miR-181c group and blank group of blank vector (no virus group). Human neuroblastoma M17 cells were added to the medium and cultured to prepare a cell suspension. The cell suspension was repeatedly blown to fully disperse the cells. Then the upper layer of agar was prepared. A total of $1.5 \mathrm{ml}$ of 100 cell suspension was transferred per dish to a small beaker at $37^{\circ} \mathrm{C}$ and $40^{\circ} \mathrm{C}, 5 \%$ agar was added in equal volume and mixed, and then added to Petri dish with the bottom agar. The mixture was incubated at $37^{\circ} \mathrm{C}, 5 \% \mathrm{CO}_{2}$ for $72 \mathrm{~h}$. There were 10 culture dishes in each group, and colony formation was observed at 24,48 and $72 \mathrm{~h}$.

Statistical analysis. SPSS 19.6 statistical software [Boyizhixun (Beijing) Information Technology Co., Ltd.] was used for the analyzing and processing the data. The basic enumeration data of patients were expressed as percentage [n (\%)], and the expression level of miR-181c as mean \pm standard deviation (mean $\pm \mathrm{SD}$ ). t-test was used for comparison between two groups. Variance analysis was used for comparison among multiple groups, and LSD test was the post hoc test used. Repeated measures ANOVA was used for comparison between different time points within a group, and LSD test was used as post hoc test. Multivariate logistic regression was used to analyze risk factors. $\mathrm{P}<0.05$ was considered to indicate a statistically significant difference.

\section{Results}

Expression levels of miR-181c in neuroblastoma cancer tissues and adjacent tissues after transfection. The results of RT-qPCR detection of miR-181c showed that the expression level of miR-181c was $0.83 \pm 0.14$ in neuroblastoma cancer tissues and $1.78 \pm 0.36$ in adjacent tissues. The expression level of miR-181c was significantly lower in cancer tissues than that in adjacent tissues, with a statistically significant difference $(\mathrm{t}=18.570, \mathrm{P}<0.001)$ (Fig. 1).



Figure 1. Expression levels of miR-181c in neuroblastoma cancer tissues and adjacent tissues. The results of RT-qPCR detection showed that the expression level of miR-181c was significantly lower in neuroblastoma cancer tissues than that in adjacent tissues, with a statistically significant difference $(\mathrm{t}=18.570, \mathrm{P}<0.001)$.

Association of miR-181c expression level with clinical and pathological features. The expression level of miR-181c was not associated with sex $(\mathrm{P}=0.632)$. miR-181c expression was lower in patients $<15$ years of age than that in patients $\geq 15$ years of age, with a statistically significant difference $(\mathrm{P}=0.003)$. miR-181c expression was lower in patients with poor differentiation than that in patients with moderate and high differentiation, with a statistically significant difference $(\mathrm{P}=0.007)$. Also, the expression of miR-181c was lower in patients with lymph node metastasis than that in patients without lymph node metastasis, with a statistically significant difference $(\mathrm{P}=0.002)$, was lower in patients with distant metastasis than that in patients without distant metastasis, with a statistically significant difference $(\mathrm{P}=0.013)$, and was lower in patients with stage M+MS than that in patients with stage L1+L2, with a statistically significant difference $(\mathrm{P}<0.001)$ (Table III).

Multivariate logistic regression analysis of neuroblastoma. Age, differentiation degree, lymph node metastasis, distant metastasis, and International Neuroblastoma Risk Group Staging System (INRGSS) were independent risk factors for neuroblastoma $(\mathrm{P}<0.05)$ (Table IV).

miR-181c transfection results. After transfection, the expression level of miR-181c in the M17 cells of miR-181c group was significantly higher than that of the blank and control 
Table III. Association of miR-181c expression with clinical and pathological features.

\begin{tabular}{|c|c|c|c|c|}
\hline Variables & $\mathrm{n}$ & miR-181c & $\mathrm{t}$ value & P-value \\
\hline Age (years) & & & 3.106 & 0.003 \\
\hline$<15$ & 45 & $0.74 \pm 0.12$ & & \\
\hline$\geq 15$ & 12 & $0.89 \pm 0.23$ & & \\
\hline Sex & & & 0.481 & 0.632 \\
\hline Male & 32 & $0.82 \pm 0.16$ & & \\
\hline Female & 25 & $0.84 \pm 0.15$ & & \\
\hline Differentiation degree & & & 2.783 & 0.007 \\
\hline Poor & 34 & $0.71 \pm 0.25$ & & \\
\hline Moderate and high & 23 & $0.87 \pm 0.14$ & & \\
\hline Lymph node metastasis & & & 3.309 & 0.002 \\
\hline Yes & 26 & $0.72 \pm 0.26$ & & \\
\hline No & 31 & $0.89 \pm 0.11$ & & \\
\hline Distant metastasis & & & 2.554 & 0.013 \\
\hline Yes & 39 & $0.74 \pm 0.15$ & & \\
\hline No & 18 & $0.87 \pm 0.23$ & & \\
\hline INRGSS & & & 3.630 & $<0.001$ \\
\hline Stage L1+L2 & 45 & $0.96 \pm 0.18$ & & \\
\hline Stage $\mathrm{M}+\mathrm{MS}$ & 12 & $0.75 \pm 0.17$ & & \\
\hline
\end{tabular}

INRGSS, International Neuroblastoma Risk Group Staging System.

Table IV. Multivariate logistic regression analysis of neuroblastoma.

\begin{tabular}{lccrrr}
\hline Factors & $\beta$ & Standard error & W & P-value & OR (95\% CI) \\
\hline Age (years) & 1.703 & 0.558 & 2.968 & 0.003 & $1.316(0.714-3.007)$ \\
Differentiation degree & 2.571 & 0.194 & 11.832 & $<0.001$ & $2.724(1.307-6.994)$ \\
Lymph node metastasis & 1.885 & 0.157 & 11.653 & $<0.001$ & $2.592(1.243-6.628)$ \\
Distant metastasis & 1.046 & 0.804 & 1.137 & 0.036 & $0.508(0.271-1.361)$ \\
INRGSS & 1.587 & 0.092 & 17.468 & $<0.001$ & $4.346(2.031-10.617)$ \\
\hline
\end{tabular}

INRGSS, International Neuroblastoma Risk Group Staging System.



Figure 2. Analysis of miR-181c transfection results. After transfection, the expression level of miR-181c in M17 cells was significantly higher in miR-181c group than that in the blank and control groups $(\mathrm{P}<0.05)$. There was no significant difference between the blank and control groups $(\mathrm{P}>0.05)$, indicating a successful transfection. ${ }^{*} \mathrm{P}<0.05$. groups $(\mathrm{P}<0.05)$. There was no significant difference between the blank and the control group $(\mathrm{P}>0.05)$, indicating that the transfection was successful (Fig. 2).

Effects of miR-181c on neuroblastoma M17 cells. Following miR-181c transfection into M17 cells, the results of MTT assay showed that there was no significant difference between the two groups in the proliferation of M17 cells at $24 \mathrm{~h}(\mathrm{P}>0.05)$. After $48 \mathrm{~h}$, differences between the two groups arose. The proliferation of M17 cells was significantly lower in the miR-181c group than that in the blank group $(\mathrm{P}<0.05)$ (Fig. 3). Following miR-181c transfection into M17 cells, the results of colony formation assay showed that there was no significant difference between the two groups $(\mathrm{P}>0.05)$. The colonies at 48 and $72 \mathrm{~h}$ in the miR-181c groups were significantly lower than those in the blank group $(\mathrm{P}<0.05)$ (Table V). 
Table V. Analysis of colony formation (\%).

\begin{tabular}{|c|c|c|c|c|}
\hline Time (h) & miR-181c group $(n=10)$ & Blank group $(n=10)$ & t value & P-value \\
\hline 24 & $10.65 \pm 5.62$ & $11.57 \pm 6.81$ & 0.329 & 0.746 \\
\hline 48 & $21.33 \pm 7.68$ & $35.65 \pm 9.66$ & 3.669 & 0.002 \\
\hline 72 & $47.25 \pm 8.54$ & $88.36 \pm 10.98$ & 9.346 & $<0.001$ \\
\hline
\end{tabular}

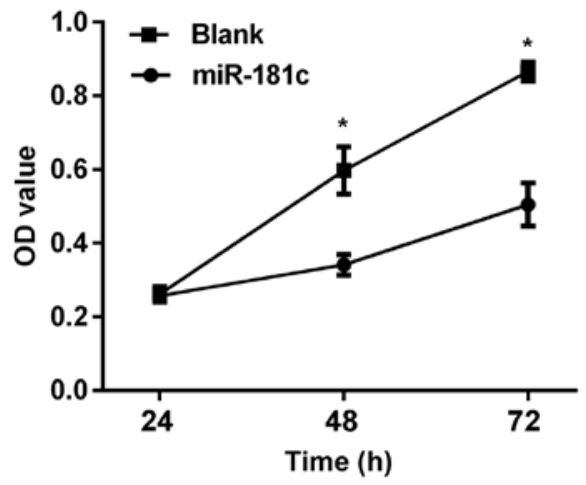

Figure 3. Effect of miR-181c on neuroblastoma M17 cells. Following miR-181c transfection into M17 cells, the results of MTT assay showed that there was no significant difference between the two groups in the proliferation of M17 cells at $24 \mathrm{~h}(\mathrm{P}>0.05)$. After $48 \mathrm{~h}$, differences between the two groups arose and the proliferation of M17 cells was significantly lower in the miR-181c group than that in the blank group, with a statistically significant difference $\left({ }^{*} \mathrm{P}<0.05\right)$.

\section{Discussion}

Neuroblastoma is a common malignant tumor in children, with increasing incidence in recent years, causing great harm to society (13). Without obvious features and specificity in early neuroblastoma, $>50 \%$ of patients have reached the high-risk status of middle and late stages when diagnosed, missing the best treatment time (14). In addition, early neuroblastoma can metastasize in children, so $>80 \%$ of patients are diagnosed with distant metastasis, resulting in poor prognosis and poor long-term survival rate (15). Therefore, finding tumor markers with high sensitivity and accuracy for neuroblastoma has become a hot research topic in clinical practice.

In this study, RT-qPCR was used to examine the miR-181c expression in neuroblastoma cancer tissues and adjacent tissues. The expression level of miR-181c was significantly lower in neuroblastoma cancer tissues than that in adjacent tissues, with a statistically significant difference. Moreover, it was found that the expression level of miR-181c was not associated with sex, but it was associated with age, differentiation degree, lymph node metastasis, distant metastasis and INRGSS, with statistically significant differences. Due to their stable biological characteristics in tissues or serum of tumor patients, miRNAs are more suitable as monitoring indicators for the diagnosis of neuroblastoma and the invasion and deterioration of tumors (16). Affecting the proliferation and differentiation of tumor cells, the expression of most oncogenes and tumor suppressor genes is associated with the occurrence, development and prognosis of tumors $(17,18)$. According to the study of Guo et al (19) on neuroblastoma, the low expression of miR-181c was significantly associated with tumor metastasis in patients, and therefore could become a clinical diagnostic marker for neuroblastoma. This is consistent with the result of the present study, that the expression of miR-181c was significantly lower in cancer tissues of neuroblastoma patients than that in adjacent tissues. After transfection of miR-181c into M17 cells, the results of MTT assay showed that there was no significant difference between the two groups in the proliferation of M17 cells at $24 \mathrm{~h}$. After $48 \mathrm{~h}$, differences between the two groups were recorded. The proliferation of M17 cells was significantly lower in the miR-181c group than that in the blank group. We showed that miR-181c can inhibit the proliferation of M17 cells, and obtained the influence and evaluation of miR-181c on neuroblastoma from the proliferation direction of M17 cells, which is a major feature of our research. Wang et al (20) showed that miRNAs, involved in all biological processes in the body, have a strong regulatory effect on the normal function of cells. They participate in the occurrence and development of multiple tumors through regulating proliferation, migration, apoptosis and angiogenesis of tumor cells (21). Our experimental results are also consistent with those of Li et al (22), according to which miR-181c inhibits cell proliferation by targeting Smad7, and its high expression in neuroblastoma cancer cells can inhibit their proliferation and differentiation. Studies have shown that miR-181c can be encoded in the nucleus, processed into a mature form in the cytoplasm, translocated into the mitochondria, thereby regulating mitochondrial gene expression (23). Other studies have shown that miR-181c overexpression can inhibit the transformation factor growth signal- $\beta$ expression, thereby inhibiting cancer cell proliferation (23). This study only used a gene in vitro to study the effects of proliferation of neuroblastoma, but did not study its mechanism, which is a future direction of the research.

In the present study, there are also some limitations as the sample size was small. Also, the clinical information was collected from neuroblastoma patients in only one hospital, so the conclusions obtained cannot fully and reliably demonstrate the overall clinical features and prognosis. Therefore, more in-depth research is needed.

Collectively, miR-181c expression was found to be low in neuroblastoma tissues, and associated with age, differentiation degree, lymph node metastasis, distant metastasis and INRGSS. Also, miR-181c was shown to inhibit the proliferation of neuroblastoma M17 cells. Therefore, miR-181c has certain clinical significance in evaluating pathogenesis, early diagnosis and treatment of neuroblastoma patients.

\section{Acknowledgements}

Not applicable. 


\section{Funding}

No funding was received.

\section{Availability of data and materials}

The datasets used and/or analyzed during the current study are available from the corresponding author on reasonable request.

\section{Authors' contributions}

XX drafted the manuscript. XX and QH performed PCR. XX and JW were responsible for the MTT assay and the soft agar colony formation assay. JW and GR collected and analyzed the patient clinical information and assisted with statistical analysis. All authors read and approved the final manuscript.

\section{Ethics approval and consent to participate}

This study was approved by the Ethics Committee of Weifang People's Hospital (Weifang, China). Patients who participated in this research had complete clinical data. Informed consents were obtained from the patients or their guardians.

\section{Patient consent for publication}

Not applicable.

\section{Competing interests}

The authors declare that they have no competing interests.

\section{References}

1. Bosse KR and Maris JM: Advances in the translational genomics of neuroblastoma: From improving risk stratification and revealing novel biology to identifying actionable genomic alterations. Cancer 122: 20-33, 2016.

2. He J, Wang F, Zhu J, Zhang R, Yang T, Zou Y and Xia H: Association of potentially functional variants in the XPG gene with neuroblastoma risk in a Chinese population. J Cell Mol Med 20: 1481-1490, 2016.

3. Ham J, Costa C, Sano R, Lochmann TL, Sennott EM, Patel NU, Dastur A, Gomez-Caraballo M, Krytska K, Hata AN, et al: Exploitation of the apoptosis-primed state of MYCN-amplified neuroblastoma to develop a potent and specific targeted therapy combination. Cancer Cell 29: 159-172, 2016.

4. Speleman F, Park JR and Henderson TO: Neuroblastoma: A tough nut to crack. Am Soc Clin Oncol Educ Book 35: e548-e557, 2016.

5. Shipley MM, Mangold CA and Szpara ML: Differentiation of the SH-SY5Y human neuroblastoma cell line. J Vis Exp 108: 53193, 2016.

6. Wilczynska A and Bushell M: The complexity of miRNAmediated repression. Cell Death Differ 22: 22-33, 2015.

7. Yuan R, Zhi Q, Zhao H, Han Y, Gao L, Wang B, Kou Z, Guo Z, He S, Xue X, et al: Upregulated expression of miR-106a by DNA hypomethylation plays an oncogenic role in hepatocellular carcinoma. Tumour Biol 36: 3093-3100, 2015.
8. Yen CS, Su ZR, Lee YP, Liu IT and Yen CJ: miR-106b promotes cancer progression in hepatitis B virus-associated hepatocellular carcinoma. World J Gastroenterol 22: 5183-5192, 2016.

9. Thind A and Wilson C: Exosomal miRNAs as cancer biomarkers and therapeutic targets. J Extracell Vesicles 5: 31292, 2016.

10. Gholamin S, Mirzaei H, Razavi SM, Hassanian SM, Saadatpour L, Masoudifar A, Shahid Sales S and Avan A: GD2-targeted immunotherapy and potential value of circulating microRNAs in neuroblastoma. J Cell Physiol 233: 866-879, 2018.

11. Maugeri M, Barbagallo D, Barbagallo C, Banelli B, Di Mauro S, Purrello F, Magro G, Ragusa M, Di Pietro C, Romani M, et al: Altered expression of miRNAs and methylation of their promoters are correlated in neuroblastoma. Oncotarget 7: 83330-83341, 2016.

12. Livak KJ and Schmittgen TD: Analysis of relative gene expression data using real-time quantitative PCR and the 2(-Delta Delta C(T)) method. Methods 25: 402-408, 2001.

13. Nalavenkata SB, Sacks R, Adappa ND, Palmer JN, Purkey MT, Feldman MD, Schlosser RJ, Snyderman CH, Wang EW, Woodworth BA, et al: Olfactory neuroblastoma: Fate of the neck - a long-term multicenter retrospective study. Otolaryngol Head Neck Surg 154: 383-389, 2016.

14. Mao Y, Eissler N, Blanc KL, Johnsen JI, Kogner P and Kiessling R: Targeting suppressive myeloid cells potentiates checkpoint inhibitors to control spontaneous neuroblastoma. Clin Cancer Res 22: 3849-3859, 2016.

15. Ho WL, Hsu WM, Huang MC, Kadomatsu K and Nakagawara A: Protein glycosylation in cancers and its potential therapeutic applications in neuroblastoma. J Hematol Oncol 9: 100, 2016

16. Mohammadi M, Goodarzi M, Jaafari MR, Mirzaei HR and Mirzaei H: Circulating microRNA: A new candidate for diagnostic biomarker in neuroblastoma. Cancer Gene Ther 23: 371-372, 2016.

17. Fish JE, Santoro MM, Morton SU, Yu S, Yeh RF, Wythe JD, Ivey KN, Bruneau BG, Stainier DY and Srivastava D: miR-126 regulates angiogenic signaling and vascular integrity. Dev Cell 15: 272-284, 2008.

18. Png KJ, Halberg N, Yoshida M and Tavazoie SF: A microRNA regulon that mediates endothelial recruitment and metastasis by cancer cells. Nature 481: 190-194, 2011.

19. Guo J, Dong Q, Fang Z, Chen X, Lu H, Wang K, Yin Y, Cai X, Zhao N, Chen J, et al: Identification of miRNAs that are associated with tumor metastasis in neuroblastoma. Cancer Biol Ther 9: 446-452, 2010.

20. Wang S, Aurora AB, Johnson BA, Qi X, McAnally J, Hill JA, Richardson JA, Bassel-Duby R and Olson EN: The endothelial-specific microRNA miR-126 governs vascular integrity and angiogenesis. Dev Cell 15: 261-271, 2008.

21. Madhavan D, Peng C, Wallwiener M, Zucknick M, Nees J, Schott S, Rudolph A, Riethdorf S, Trumpp A, Pantel K, et al: Circulating miRNAs with prognostic value in metastatic breast cancer and for early detection of metastasis. Carcinogenesis 37: 461-470, 2016.

22. Li Y, Wang H, Li J and Yue W: MiR-181c modulates the proliferation, migration, and invasion of neuroblastoma cells by targeting Smad7. Acta Biochim Biophys Sin (Shanghai) 46: 48-55, 2014.

23. Das S, Bedja D, Campbell N, Dunkerly B, Chenna V, Maitra A and Steenbergen C: miR-181c regulates the mitochondrial genome, bioenergetics, and propensity for heart failure in vivo. PLoS One 9: e96820, 2014.

This work is licensed under a Creative Commons Attribution-NonCommercial-NoDerivatives 4.0 International (CC BY-NC-ND 4.0) License. 